\title{
A CRIANÇA EM WALTER BENJAMIN: A ARTE DA BRINCADEIRA E O INTEIRAMENTE NOVO
}

Paulo Victor de Albuquerque Silva

\begin{abstract}
RESUMO
Com um percurso na história da criação do brinquedo e sua adequação ao público infantil, Benjamin observa que, antes, se deve à criatividade da própria criança a reelaboração e adaptação desses objetos ao "fervor" da brincadeira. No contra fluxo dos pressupostos da cultura, a arte de brincar desafia o material elaborado pela mente adulta destinado à ludicidade.
\end{abstract}

Palavras-chaves: Brinquedo. Brincadeira. Lúdico. Potencial feérico. Benjamin

\section{THE CHILD IN WALTER BENJAMIN: THE ART OF PLAYING AND ENTIRELY NEW}

\begin{abstract}
Passing through the history of the creation of toys and it's adequacy to suitability for the children, Benjamin remarks that it is due to child's own creativity the redesign and adaptation of these objects while playing with them. Against the postulates of the culture, the art of playing challenges the material created by the adult mind for recreation purposes.
\end{abstract}

Keywords: Toys. Games recreation. Playful. Faulty potencial. Benjamin

Tendo em vista compreendermos a extensão do mundo infantil, no contra fluxo da imagens suscitadas pela rua de mão única (Einbahnstrasse), constituiremos a imagem da infância, acenando a um aparato que se encontra presente em todas as instâncias da realidade da criança: o brinquedo. Pois nesse objeto se concentra unicamente seu caráter lúdico no momento em que é utilizado no jogo. Mesmo que em outras instâncias seja empregado de diversos modos, enquanto brinquedo, 
sublima-se na vida feérica. Pensar a relação entre criança e brinquedos não se reduz exclusivamente a esse ato específico, antes nos apresenta o modo como a infância confronta-se com a existência circundante. Estamos nos referindo à arte do brincar. Também podemos investigar que material mais convém a sua constituição e a seus detalhes, como objeto de manifestação lúdica. É claro que, enquanto manifestação do espírito humano, os brinquedos são resultado de criação histórica, daí fazer-se necessário o entendimento do modo de sua produção pelos adultos e receptação pelos pequeninos. Petendemos expor quem em último caso determina a brincadeira infantil, se a criança através de sua criatividade ou o brinquedo em sua concretude material.

Para começarmos falando sobre os objetos lúdicos devemos nos remeter a um texto de Benjamin de 1928 "Velhos brinquedos: sobre a exposição de brinquedos no Märkische Museum", logo após o filósofo se deparar com uma exposição, neste mesmo ano, concentrada no "Museu distrital brandenburguês" referente aos velhos brinquedos das antigas famílias locais de Berlim. A exibição, em momento algum, pretendia expor objetos megalomaníacos que satisfizessem os mais tortuosos desejos do público adulto, mas apresentava uma gama de obras dos artesãos manufatureiros da Alemanha do século XVIII e XIX. Tal exposição foi de extrema importância para despertar em Benjamin sua curiosidade e alavancar seus estudos sobre os brinquedos infantis - fato observável quando o mesmo se depara com a obra de Karl Gröber ${ }^{1}$ e decide escrever, por sua vez, "História cultural do brinquedo" também em 1928.

Se pensarmos na origem da produção de brinquedos perceberemos que 0 surgimento de sua fabricação especializada demorou vários anos para vir à tona. Antes, principalmente entre o século XVIII e XIX, quem detinha tal responsabilidade no seu fabril eram os pequenos comerciantes manufatureiros, que quando ociosos dispunham-se a elaborar miniaturas jocosas. "Seus precursores são, por um lado, os vendedores de artigos de marcenaria, assim como os vendedores de ferragens, papéis e enfeites; por outro lado, os mascates de cidades e feiras." (BENJAMIN, 2002, 82). A variedade de produtos se dava na mesma proporção que o trabalho especializado se diversificava, tudo aquilo que era feito como mercadoria para os

\footnotetext{
${ }^{1}$ Karl Gröber, obra com o título "Kinderspelzeug aus alter Zeit. Eine Geschichte des Speilzeugs. [Brinquedos infantis de velhos tempos. Uma história do brinquedo, escrita no mesmo ano, 1928.

Mestrando pela Universidade Estadual do Ceará (UECE). Brasileiro, residente em Fortaleza-CE. 
adultos, no tempo livre, passava a ser reproduzido em miniatura para os pequeninos. Assim, facilmente poder-se-ia encontrar em meio às prateleiras de uma confeitaria um fabuloso boneco de guloseimas que chamava atenção de crianças e adultos, é o caso da boneca feita de resina. Anúncios nas postas das lojas atraiam todos a se deliciarem com tais objetos bucólicos que aos poucos adentravam o mundo que em pouco tempo seria coberto pelo luxo fantasmagórico, Essa junção posteriormente conotará uma maior força em sua exposição. Para Benjamin somos introduzidos no mundo lúdico, antes de mais nada, por meio do espetáculo fantasioso das cores, que no século XIX eram exploradas pelas câmeras ópticas, os dioramas, minioramas, panoramas, todos em sua maioria fabricados na cidade de Augsburgo. "Já não se tem mais isso', ouve-se com frequência o adulto dizer, ao avistar brinquedos antigos." (BENJAMIN, 2002, 84). O filósofo nos fala que essa afirmação do maior não passa de mera impressão, já que ele perdeu, com o passar dos anos, sua capacidade de perceber a ludicidade em tais objetos, agora indiferentes ao mesmo, mas magníficos para a criança. Com isso defendemos que o olhar desviante e fabuloso da infância reconhece com maior facilidade o potencial feérico existente no mundo, ação extremamente complicada para o adulto que se encontra enjaulado no pragmatismo linguístico que ceifou sua imaginação pueril. É evidente que algumas mercadorias deixam de existir para que outras tomem o seu lugar, como no caso dos panoramas, mas isso não impede que, nesses modernos objetos, o jogo de cores seja novamente explorado sobre formas variantes e igualmente fantasiosas.

Como foi dito, até o século XIX a produção de brinquedos não se dava de forma especializada, por conta disso nos mais variados ramos de fabricação podia-se encontrar esses objetos em formatos e materiais distintos. Como as oficinas manufatureiras continham objetivos específicos para sua criação, pois estavam proibidas pelos estatutos corporativos de enfrentarem novos horizontes, o formato e o estilo dessas peças ganhavam aspectos próprios. Isso levava os fabricantes a reproduzirem em suas obras aquilo que era proposto em seu trabalho diário. Tal proximidade com a realidade fabril unia as crianças junto ao processo de fabricação. A proibição das corporações fez com que o preço dos primeiros brinquedos encarecesse durante o século XVIII, já que cada profissional ficava responsável em produzir uma parte da produção. "Por conseguinte, entende-se por si só, que a venda ou, pelo menos, a distribuição de brinquedos não era, no início, função de 
comerciantes específicos." (BENJAMIN, 2002, 90). Durante o século XIX a venda de brinquedos somente veio a se tornar paulatinamente um ramo da indústria com 0 reconhecimento da infância. Antes de tudo, fez identificar nesse público mais um potencial consumidor.

A retomada dos brinquedos antigos pelos adultos levanta diversas questões que nos levam a pensá-los sob variados aspectos. Esses podem ser avaliados, por exemplo, a partir da psicanálise, folclore, história da arte, antropologia, economia e em nosso caso, da filosofia. Benjamin, por sua vez, procura entender: Por que o contato com os brinquedos antigos, como no caso da exposição no Märkische Museum, o brinquedo passa a ser objeto de desejo dos adultos que se dispõem a contemplá-los? Dentre todos os estímulos lúdicos para os maduros, com certeza, o mais decisivo nisso tudo é o momento, ou a imagem famosa, em que o mesmo encontra-se absorto com o brinquedo que acabara de entregar ao seu filho. $\mathrm{O}$ adulto, quando brinca, não experimenta o mesmo prazer que a infância, bem como não adentra em uma introspecção regressiva que o levaria aos meandros de sua meninice. No seu ato de brincar, o velho se liberta das correntes adornadas pelo cotidiano, abre uma fenda no real. "Rodeados por um mundo de gigantes, as crianças criam para si, brincando, o pequeno mundo próprio; mas o adulto, que se vê acossado por uma realidade ameaçadora, sem perspectivas de solução, liberta-se dos horrores do real (...)." (BENJAMIN, 2002, 85). A reprodução miniaturizada da realidade transmite a impressão de amadurecido de controle sobre os objetos, o mundo caótico imediato transplanta-se para dentro do jogo numa cosmogonia humana. $\mathrm{O}$ adulto sente por alguns instantes o poder soberano pertencente apenas à criança liberta. Para o filósofo, o interesse crescente no pós-guerra. por jogos e livros infantis é nitidamente a tentativa de escape da "existência insuportável" e sua "temporalidade do inferno". Tal necessidade do crescido transporta para o brinquedo uma formatação que assegura suas penúrias, com isso vemos surgir objetos que escapam do lúdico infantil.

Devemos ter em mente que essa influência do mundo adulto na produção de brinquedos para os pequeninos não se dava em vão. É do conhecimento de todos a antiga visão sobre as crianças como sendo pequenos adultos, fato que podia ser bem observado nas bonecas vestidas com trajes formais e maduros. $O$ reconhecimento da vida infantil acompanha a emancipação do fabril de brinquedos que agora respeita 
suas exigências. Identificar a criança em sua singularidade não denota infantilizar a infância, mas garantir a plenitude do seu potencial. Os pequenos seres, assim como todo e qualquer humano, contém em seu âmago um lado obscuro e funesto que não pode ser posto à margem de nossa reflexão. "Enquanto cândidos pedagogos permanecem nostálgicos de sonhos rousseaunianos, escritores como Joachim Ringelnatz, pintores como Paul Klee, captaram o elemento despótico e desumano nas crianças. As crianças são insolentes e alheias ao mundo." (BENJAMIN, 2002, 86). A capacidade de escapar da realidade e reconstruir o mundo a sua maneira é a máxima do poder tirânico e inovador da criança. Benjamin ainda defende o posicionamento teórico do filósofo neokantiano Salomo Friedlaender, que sustenta a ideia de que se pretendemos ser responsáveis pela formação integral dos indivíduos temos que levar em consideração todas as facetas do caráter humano, nada pode ser escondido. Tal atributo pode muito bem ser percebido nas mais variadas brincadeiras infantis que desvelam seu lado sagaz, o que leva nosso autor a citar Friedlaender com a seguinte fala: "'Bonecas-vítimas que podem ser assassinadas das mais diversas formas e seus correspondentes assassinos com todos os respectivos instrumentos; guilhotina e forca: pelo menos os meus pequenos não querem mais prescindir de nada disso.'” (BENJAMIN, 2002, 87). Esse poder exercido pela criança em um controle absoluto sobre seu mundo ainda será mais explorado no próximo tópico, mas o que nos fica de aprendizado é o espelho no qual a infância se reflete para a intimidade humana. Tudo emana dela, ser límpido e direto, sem mistérios obscuros. A plenitude da criatura germina nessas pequenas sementes.

Podemos perceber com o passar dos anos, à medida que a criança passou a ser reconhecida em sua singularidade, cada vez mais o adulto desprender atenção à produção dos brinquedos e jogos infantis. De posse do brinquedo a criança manipulao livremente adequando o objeto a suas criativas pretensões. "(...) jamais são os adultos que executam a correção mais eficaz dos brinquedos - sejam eles pedagogos, fabricantes ou literatos -, mas as crianças mesmas, no próprio ato de brincar." (BENJAMIN, 2002, 87). O brinquedo nas mãos de uma criança jamais se encontrará completo e acabado, ele é uma incógnita que será desvendada e reconstruída pelo pequenino.

Voltando a explorar o modo de fabricação dos brinquedos, Benjamin expõe, no texto "História cultural do brinquedo", como se deu a transição das oficinas 
manufatureiras até sua produção especializada. Neste contexto um fator de extrema relevância foi por influência da marcante reforma protestante, com o deslocamento dos pequenos artistas. Eles passaram a produzir pequenas decorações domésticas, já que perderam seu lugar nas obras pertencentes à igreja católica. Com isso as residências foram ocupadas por um mundo de "coisas minúsculas" (BENJAMIN, 2002, 91), que além de servirem como fonte de decoração expositiva para os adultos, eram verdadeiras fortunas capazes de serem incorporadas, facilmente, ao jogo dos pequeninos, por conta de seu tamanho. Neste momento devemos nos ocupar mais designadamente da questão do formato dos brinquedos e da sua relevância no momento do jogo, e, com isso, ampliar nossa compreensão da magnitude do campo de ação da ludicidade infantil. A pequenez dos objetos é um fator de extrema importância para a apropriação da criança em sua autoridade construtiva, pois faz-se necessário o livre manuseio das coisas, num processo de criação liberto e dilatado. Qualquer artifício que antes de expandir, restrinja o potencial criador logo será renunciado pela criança. Os feitos de acrescentamento dos brinquedos que veremos surgir com os anos não retratam uma aproximação da infância, muito pelo contrário. "Com efeito, na segunda metade do século XIX, quando começa a acentuada decadência daquelas coisas, percebe-se como os brinquedos se tornam maiores, vão perdendo aos poucos o elemento discreto, minúsculo, sonhador." (BENJAMIN, 2002, 91). O tamanho do brinquedo deve caber dentro do sonho lúdico das crianças. Tudo pode ser admirado, mas nem tudo pertencerá às vísceras da realidade feérica.

Com o aumento do formato dos brinquedos consecutivamente vemos surgir uma nova relação com os mesmos, fato que se evidência no comportamento tanto das crianças quanto dos adultos. Assim como toda massa existente na amplidão do universo altera as demais matérias que se encontram ao seu redor, sendo maior sua influência quanto mais larga sua circunferência, também os brinquedos passaram a transformar a espacialidade da residência no século XIX, forçando até mesmo o surgimento de um quarto próprio para tais objetos. É claro que sua "massa gravitacional" interferiu na vida casual como um todo. "(...) em seus pequenos formatos, os voluminhos mais antigos exigiam a presença da mãe de maneira muito mais íntima; os volumes in quarto mais recentes, em sua insípida e dilatada ternura, estão antes determinados a fazer vista grossa à ausência materna." (BENJAMIN, 2002, 91). A "massa gravitacional" dos grandes brinquedos pode até atrair a matéria, 
mas o mesmo não ocorre com as crianças. Esse processo de emancipação do brinquedo proposto pela industrialização avançada torna tais objetos estranhos a pais e filhos. Agora brotam sob nossos olhos entidades com um alto grau de complexidade que em seu poder possuem o direcionamento do jogo. A presença da mãe ou do pai não se faz mais necessária. Estes objetos contemplam em si as maravilhas do brincar. Antes, os bibelôs de decoração emancipavam-se da exposição pelas mãos da criança. Depois dos brinquedos in quarto, esses bibelôs viram o seu salvador desbravando outros mundos no cômodo ao lado, mas a profecia nos conta que seu retorno está próximo.

O fim da produção manufatureira era algo inevitável, aja vista o que historicamente ocorreu com os outros modos de produções rudimentares. Aqueles que ainda resistem, são uma minoria escassa que, a dura labuta, sobrevivem. Em vários casos, seus produtos são considerados objetos raros servindo no máximo para exposição. A fabricação industrial dos brinquedos modernos transmite o que Benjamin chama de "falsa simplicidade", pois nela somos relegados a manter contato com o seu processo de criação. A distância entre a criança e o processo de constituição do brinquedo dificulta a relação do último com os pequeninos. Quanto mais clara for cada etapa de montagem, maior a compreensão do objeto tendo em vista o controle de sua manipulação. A criança, para brincar, deseja primeiro conhecer por inteiro o artefato que se encontra em suas mãos. Por conta disso não é de se estranhar quando um pequenino se depara com mercadorias complexas e procura despedaça-las minuciosamente para entendê-la. Benjamin é muito enfático quando defende a utilização de materiais e técnicas simples na fabricação dos brinquedos. Nada melhor para a infância. Por conta disso o filósofo propõe que a madeira seja utilizada na produção dos objetos lúdicos, pois apresenta tanto maior resistência quanto capacidade em assimilar cores. No ato de brincar a criança relaciona-se com a matéria de um modo que o ensaísta chama de "relação antinômica", que se trata de uma dupla conexão. Por um lado "(...) nada é mais adequado à criança do que irmanar em suas construções os matérias mais heterogêneos - pedras, plastilina, madeira, papel." (BENJAMIN, 2002, 92). A riqueza de apetrechos valoriza a criação lúdica, mas também podemos afirmar por outro lado, "(...) um simples pedacinho de madeira, uma pinha ou uma pedrinha reúnem na solidez, no monolitismo de sua matéria, uma exuberância das mais diferentes figuras." (BENJAMIN, 2002, 91). A "relação 
antinômica" se produz nessa duplicidade, a valorização da diversidade material bem como sua singularidade. Seja em qual material for, o que importa é o domínio do pequeno ser sobre as coisas, sua manipulação livre dando asas à sua imaginação. Neste sentido quando os adultos pensam para as crianças brinquedos feitos dos materiais mais frágeis possíveis, eles estão decodificando a sensibilidade infantil sob sua perspectiva, que já se encontra apossada pelo espetáculo simbólico que nos rodeia. Tais brinquedos passam então a refletir muito mais as "argúcias teológicas" da mercadoria de um público adulto consumidor das luxuosidades fantasmagóricas do capital. É a materialização do espírito capitalista em seu tempo.

Após o reconhecimento da infância muitos estudos passaram a se desenvolver em torno de sua individualidade, foi o que aconteceu com as análises da psicologia por exemplo, em busca de desvendar esse novo ser que sempre se encontrava lá, mas que caminhava a passos rasteiros, sem ser percebido. Com o século $X X$ os investigadores começam a distinguir o lado coletivo do fenômeno infantil, retirandoIhe dessa bolha invisível, onde acreditavam que a infância habitasse e conseguem finalmente enxergar a criança como parte da totalidade social, é o caso de Walter Benjamin e Karl Gröber. "É que, assim como o mundo da percepção infantil está impregnado em toda parte pelos vestígios da geração mais velha, com os quais as crianças se defrontam, assim também ocorre com os seus jogos." (BENJAMIN, 2002, 96). Grande parte dos jogos infantis não foi criado por aqueles que os praticam. São atividades que se repetem e se propagam ao longo dos anos entre as gerações. $O$ jogo é uma construção coletiva, proveniente do tecido social das décadas. Nele a criança se reveste com a contextura costurada pelas eras, reflexo da cultura manifesta em rimas, gestos, sinais. Qualquer desconstrução do ritual ancestral representa ruptura com a tradição. A criança não pode ser vista como um ser imaculado, distante do mundo humano e restrita a seus devaneios feéricos. Antes ela se encontra entre nós num combate constante com o "espírito do tempo". "O brinquedo, mesmo quando não imita os instrumentos dos adultos, é confronto, e, na verdade, não tanto da criança com os adultos, mas destes com a criança." (BENJAMIN, 2002, 96). O brinquedo jamais chegará pronto nas mãos dos pequeninos, somente eles completarão seus últimos ajustes, mudanças demasiadamente caras para a tradição.

A "força da imaginação infantil" (BENJAMIN, 2002, 96) é capaz de arruinar com 
as pretensões da tradição, quando oferecem à criança objetos que previamente deveriam ser cultuados por todos. Para Benjamin, vários objetos que hoje são considerados brinquedos, antes somente eram instrumentos fetichistas de culto religioso, como no caso da bola, do arco, roda de penas, pipa, etc. Foi através da criança, e não do desejo adulto, que se transformaram em objetos lúdicos. E por mais que psicanalistas ou pedagogos matutem, sem nenhuma conclusão plausível, acerca dos motivos para a invenção, e até o modo como essas coisas interferem na vida infantil, os pequenos brincam com esses objetos do modo mais despretensioso e incoerente. "Há portanto um grande equívoco na suposição de que são simplesmente as próprias crianças, movidas pelas suas necessidades, que determinam todos os brinquedos." (BENJAMIN, 2002, 96 - 97). Elas produzem seus brinquedos por meio do confronto direto com o adulto. O grande ataca a criança com suas armas do espírito moderno, descarregando-as sobre elas. Sua munição é o iluminismo, o progresso, a técnica. Os pequeninos respondem, não retirando a munição, mas destruindo as próprias armas. Nas mãos das crianças os brinquedos tornam-se objetos subordinados à sua soberania.

Até o século XIX a inteligência do bebê era totalmente desconhecida e os seres maduros deveriam servir de exemplo para a formação dos pequenos. Aquele velho ideal da criança como um pequeno adulto é proveniente do racionalismo iluminista que centraliza toda a produção do conhecimento no amadurecido. Tal ideal de certa forma fez com que o público infantil fosse tratado com maior seriedade. Em contrapartida o homem burguês, sem saber como lidar com esses novos seres, compensou sua ignorância realizando a construção de brinquedos em grandes formatos. "A jovialidade oriunda da consciência de culpa impõe-se sobretudo com as tolas distorções para dimensões maiores e mais largas." (BENJAMIN, 2002, 98). A burguesia propôs compensar todos os anos em que socialmente as crianças se mantiveram distantes do convívio social através do tamanho dos brinquedos. Para Benjamin a caricatura do capital mercantil está claramente expressa em uma loja de brinquedos do início do século XX. Como resposta, as oficinas artesanais que ainda resistiam, procuravam responder ao movimento avassalador da indústria através da "simplicidade" do brinquedo. A simplicidade se refere, não ao material utilizado, mas ao modo de produção, ao qual foi exposto o brinquedo, representação do caráter de 
classe.

\begin{abstract}
O espírito do qual descendem os produtos, o processo total de sua produção, e não apenas o seu resultado, está sempre presente para a criança no brinquedo, e é natural que ela compreenda muito melhor um objeto produzido por técnicas primitivas do que um outro que se origina de um método industrial complicado. (BENJAMIN, 2002, 127).
\end{abstract}

Tudo para a criança é novo, daí a necessidade em compreender qualquer coisa que the salta a consciência. A apreensão da matéria é de extrema importância para ela, pois esse é o único modo de manter sua soberania sobre as coisas, para então afirmar-se no mundo, a sua maneira. Por conta disso os brinquedos industrializados permanecem, em vários momentos, à margem da atenção dos pequeninos, e quando recebem sua vigilância sofrem severas alterações em sua estrutura prévia. As crianças adoram imaginar de que maneira os seus brinquedos foram produzidos, a simplicidade aqui é crucial para tanto. "É exatamente isso que a criança deseja saber, é isso que estabelece uma relação viva com suas coisas." (BENJAMIN, 2002, 127). Podemos afirmar que é neste ponto que se evidencia o sex appeal do inorgânico na infância. O desejo pelas coisas inanimadas está na origem da libido infantil. Essas coisas logo ganham vida nas portas de sua imaginação. A atração pela mercadoria fetichista sustentada pelo sex appeal não se manifesta da mesma maneira em relação a criança e a adulto. Na primeira o desejo aparece visando o envolvimento cognitivo com a matéria, e em última instância provoca a profanação do objeto sacramentado; no segundo a libido sustenta-se, ao contrário, pela admiração ao desconhecido, alienação acerca do processo produtivo.

Um texto de 1930 com o título "Elogio da boneca: Glosas críticas a Bonecas e teatro de marionetes, de Max von Boehn", nos ajudará a melhor compreender um pouco mais a relação sexual com os brinquedos. A certa altura do texto Benjamin escreve sobre a conexão feita por Boehn entre os polos, amor e jogo, presentes no mundo das bonecas: "Pouco sabe ele do espírito do jogo, e aquilo que nos trouxe do outro hemisfério é escasso - deve ser visto sob a divisa 'fetichismo da boneca'." (BENJAMIN, 2002, 133). Os brinquedos também são fonte do desejo fetichista, nisso eles enlaçam a perigosa congruência sintetizada entre o amor e o jogo. Podemos concluir que por trás de todo jogo existe uma centelha de desejo que pulsa em todos os indivíduos. Pouco mais a frente diz o autor: "É o próprio desejo, o desejo 
enlouquecido, e o seu ideal é a boneca. Ou não seria antes o cadáver?" (BENJAMIN, 2002,133 -134). A boneca aqui é representada pela figura do cadáver, que além de emblema da finitude humana, carrega consigo o inanimado, o inorgânico, sem vida. A máxima "até que a morte nos separe" é agora conservada e materializada no pequeno cadáver que se encontra no quarto de um colecionador. As crianças conseguem rapidamente se desvencilhar de um possível amor se ligando a outros tais variados, mas é esse Eros pelo mundo inorgânico que as aproximam do colecionador. "Pois criança e colecionador, até mesmo criança e fetichista - ambos situam-se em um mesmo terreno, mas certamente em lados diferentes do maciço escarpado e fragmentado da experiência sexual." (BENJAMIN, 2002, 134). Se no adulto a sexualidade é estimulada pelo aparato fetichista tecnológico da mercadoria a sexualidade na infância, ao contrário, visa a uma compreensão cognitiva do objeto desejado.

\section{REFERÊNCIAS}

ARENDT, H. Origens do Totalitarismo. Tradução de Roberto Raposo. São Paulo: Companhia das Letras, 2006.

BENJAMIN, Walter. A hora das crianças: narrativas radiofônicas. Tradução de Aldo Medeiros, Rio de Janeiro: NAU Editora, 2015.

BENJAMIN, Walter. Magia e Técnica, Arte e Política - Obras escolhidas I, Tradução de Sérgio Paulo Rouanet, São Paulo: Editora Brasiliense, 1985.

BENJAMIN, Walter. Rua de mão única - Obras escolhidas II. Tradução de Rubens Rodrigues Torres Filho e José Carlos Martins Barbosa, São Paulo: Editora Brasiliense, 1987.

BENJAMIN, Walter. O capitalismo como religião. Tradução de Nélio Schneider, Renato Ribeiro Pompeu, São Paulo: Boitempo, 2013.

BENJAMIN, Walter. Escritos sobre mito e linguagem. Tradução de Susana Kampff Lages e Ernani Chaves. São Paulo: Duas Cidades; Ed. 34, 2011.

BENJAMIN, Walter. Origem do drama barroco alemão. Tradução de Sérgio Paulo Rouanet, São Paulo: Editora Brasiliense, 1984.

BENJAMIN, Walter. Reflexões sobre a criança, o brinquedo, a educação. Tradução de Marcus Vinicius Mazzari, São Paulo: Duas Cidades, Editora 34, 2009.

BENJAMIN, Walter. Passagens. Tradução do alemão Irene Aron; tradução do Mestrando pela Universidade Estadual do Ceará (UECE). Brasileiro, residente em Fortaleza-CE. 
francês Cleonice Paes Barreto Mourão. Belo Horizonte: Editora UFMG. 2009.

BENJAMIN, Walter. Rua de mão única: Infância berlinense: 1900. Tradução de João Barrento. Belo Horizonte: Autêntica Editora, 2013.

BENJAMIN, Walter. Écrits français. Paris, éd. Gallimard, 2011.

CALLADO, Tereza de Castro. Walter Benjamin - A Experiência da Origem. Fortaleza: Eduece, 2006.

CALLADO, Tereza de Castro. "A Unidade do particular e as arestas da consciência no projeto de uma política vindoura" in:_Cadernos Walter Benjamin N. 10 - JaneiroJunho de 2013, acessível no site: www.gewebe.com.br

FREUD, Sigmund. Além do princípio de prazer, psicologia de grupo e outros trabalhos. Tradução de Eudoro Augusto Macieira de Souza. Rio de Janeiro: Imago, 2006.

GUTTON, Philippe. O brincar da criança: estudo sobre o desenvolvimento infantil. Tradução de Sonia Fuhrmann. Petrópolis, RJ: Vozes, 2013.

HUIZINGA, Johan. Homo ludens: o jogo como elemento da cultura. Tradução de João Paulo Monteiro. São Paulo: Perspectiva, 2014.

KANT, Immanuel. Sobre a Pedagogia. Tradução de Francisco Cock Fontanella. Piraricaba: Editora Unimep, 1999.

KRAMER, Sonia. LEITE, Maria Isabel Ferraz Pereira. Infância e produção cultural. Campinas. SP: Papirus, 1998.

MITROVITCH, Caroline. Experiência e formação em Walter Benjamin. São Paulo: Editora Unesp, 2011 